
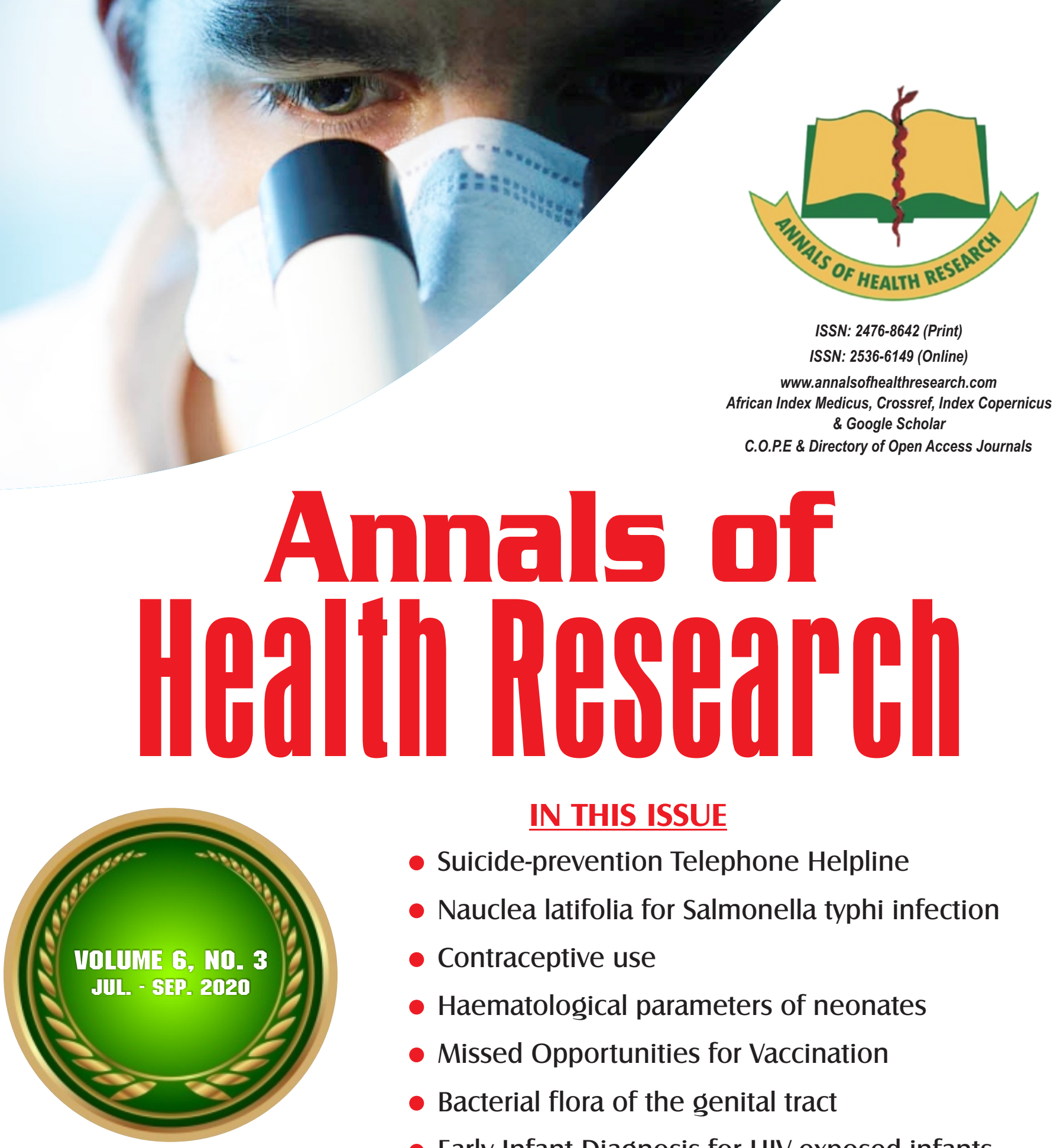

IN THIS ISSUE

- Suicide-prevention Telephone Helpline

- Nauclea latifolia for Salmonella typhi infection

- Contraceptive use

- Haematological parameters of neonates

- Missed Opportunities for Vaccination

- Bacterial flora of the genital tract

- Early Infant Diagnosis for HIV-exposed infants

- Bone markers and cardiovascular risk factors

- Attitude to termination of pregnancies

- Herpes zoster ophthalmicus

- Neonatal hyperinsulinaemic hypoglycaemia

- Paediatric perineal injury

PUBLISHED BY THE MEDICAL

AND DENTAL CONSULTANTS ASSOCIATION

OF NIGERIA, OOUTH, SAGAMU, NIGERIA.

www.mdcan.oouth.org.ng 


\title{
Antibacterial activity of crude extracts of the leaves of Nauclea latifolia Smith (Rubiaceae) and some selected conventional antibiotics on clinical isolates of Salmonella typhi Okunye OL ${ }^{* 1}$, Idowu PA², Kolade TT ${ }^{3}$
}

${ }^{1}$ Department of Pharmaceutical Microbiology, Faculty of Pharmacy, Olabisi Onabanjo University, Ogun State, Nigeria 2Department of Pharmaceutical Microbiology, Faculty of Pharmacy, University of Ibadan, Ibadan, Nigeria ${ }^{3}$ Department of Biological Science, Yaba College of Technology, Yaba, Lagos, Nigeria

*Correspondence: Dr OL Okunye, Department of Pharmaceutical Microbiology, Faculty of Pharmacy, Olabisi Onabanjo University, Ogun State, Nigeria. E-mail: femfem111@yahoo.com; ORCID - https://orcid.org/0000-0001-6444-563X.

\begin{abstract}
Background: Nauclea latifolia Smith (Rubiaceae) is a valuable medicinal plant used in folkloric medicine in the treatment of Typhoid fever. The public health significance of Salmonella typhi, the aetiologic agent in typhoid fever lies in the increasing resistance to antimicrobial agents.

Objectives: To determine the antimicrobial potentials of the crude extracts of the leaves of Nauclea latifolia on clinical isolates of Salmonella typhi compared with some conventional antibiotics.

Methods: Antibiogram was carried out on 25 biochemically confirmed clinical isolates of Salmonella typhi using disc diffusion method of Kirby Bauer. Nauclea latifolia leaves extracted with ethyl acetate and methanol in a Soxhlet apparatus were screened for secondary metabolites. The minimum inhibitory concentrations (MICs) of the extracts were determined by agar dilution method on the isolates.

Results: The antibiogram of Samonella typhi showed the following resistance patterns: Augmentin ${ }^{\circledR}(24.0 \%)$, amoxicillin (44.0\%), chloramphenicol (32.0\%), gentamicin $(20.0 \%)$, cloxacillin (96.0\%), ciprofloxacin (8.0\%), erythromycin $(60.0 \%)$, tetracycline $(32.0 \%)$ and cotrimoxazole $(60.0 \%)$. The extracts showed good antibacterial activity on the clinical isolates including those resistant to antibiotics. The MIC of methanol extract ranged from $1.56 \mathrm{mg} / \mathrm{ml}$ to $6.25 \mathrm{mg} / \mathrm{ml}$ and $3.13 \mathrm{mg} / \mathrm{ml}$ to $25.0 \mathrm{mg} / \mathrm{ml}$ for ethyl acetate extract with the exception of isolates 11,12 , 19 and 20 with high MIC values as $50 \mathrm{mg} / \mathrm{ml}$. The methanol and ethyl acetate extracts gave a yield of $11.7 \%$ and $3.5 \%$ respectively. Bioactive secondary metabolites were detected from the extracts.

Conclusion: The crude extracts of the leaves of Nauclea latifolia contained antimicrobial agents that were active on Salmonella typhi which could be used alone and in supportive with conventional antibiotics for therapeutic management of typhoid fever
\end{abstract}

Keywords: Antibiotics, Antimicrobial activity, Nauclea latifolia, Salmonella typhi, Typhoid fever. 


\section{Introduction}

Nauclea latifolia Smith (Rubiaceae), known as the African peach and "Egbesi" in Yorubaland, is a spreading, evergreen, multi-stemmed shrub that is native to tropical Africa and Asia. It is used for the treatment of various ailments including bacterial diseases by traditional medical practitioners. It is most effective against Corynebacterium diphtheriae, Neisseria spp., Pseudomonas aeruginosa and Salmonella spp. Leaf decoctions of Nauclea latifolia are used in the treatment of typhoid fever. The extracts of different parts of Nauclea latifolia in hot water or alcohol are used in forms of infusions, decoctions or concoctions. ${ }^{[1]}$

Typhoid fever, caused by Salmonella enteric serovar Typhi, remains an important public health challenge, particularly in low-income countries with approximately 10 million cases and about 700,000 deaths annually. Typhoid fever affects both young children and adults in Nigeria. [2] Salmonella typhi is contracted through ingestion of contaminated water, food, feeds and poultry products or direct faeco-oral spread in children. Salmonella typhi and Salmonella paratyphi are serotypes that are highly adapted to man and do not cause disease in non-human hosts. [3]

Chloramphenicol, amoxicillin, ampicillin, cotrimoxazole and ciprofloxacin are the mainstay of antibiotic treatment of typhoid fever in developing countries. Within a decade of discovery and use of chloramphenicol, many strains of Salmonella have developed resistance to the drug hence the substitution of ampicillin, amoxicillin, cotrimoxazole and tetracycline. Since the 1990s, there has been an increasing prevalence of multidrug resistance to most of the antibiotics in use, thereby causing a shift in choice of drugs for the treatment of typhoid fever to fluoroquinolones in Africa and Indian parts of Asia. ${ }^{4]}$ Factors such as overpopulation, poor supplies of potable water, indiscriminate use of antibiotics and overburdened healthcare systems contribute to the development of antibiotic-resistant strains of Salmonella typhi. [5]

Herbal treatment of diseases has been in practice from time immemorial and it is gaining popularity worldwide due to affordability, availability and increasing knowledge of uses and efficacy. According to the World Health Organisation (WHO), approximately $80 \%$ of the global population relies on traditional medicines for their primary health upkeep, while developed countries are also actively involved in the use of plant-derived products for medical purposes. ${ }^{[6]}$ Approximately $12.5 \%$ of the 422,000 plant species archived worldwide had been shown to have medicinal values. Many medicinal plants have potential antimicrobial activity and can as well be a source of new antiinfectious agents hence, the increasing search for new antimicrobial agents among natural products. [7] Therefore, this study was designed to determine the therapeutic potency of the crude extracts of Nauclea latifolia leaves on clinical isolates of Salmonella typhi obtained from cases of typhoid fever in comparison with selected conventional antibiotics.

\section{Methods}

Collection of clinical isolates

Clinical isolates of Salmonella typhi were obtained from cases of gastrointestinal complications from the Medical Microbiology Laboratory units of the Saint Mary Hospital Eleta and Our Lady of Apostles Hospital, Oluyoro, both in Ibadan, Nigeria. The isolates were confirmed as Salmonella typhi by subculturing on Salmonella-Shigella agar, macroscopic examination for morphological characteristics, Gram staining, motility test and other conventional biochemical investigations. 


\section{Determination of antibiogram}

Antimicrobial susceptibility profiles of the bacterial isolates were determined using the agar diffusion method of Kirby Bauer. Three to five colonies of the overnight culture of the strains were inoculated into a tube containing Tryptone Soy Broth and were incubated for 24 hours at $37^{\circ} \mathrm{C}$. The inoculums were standardized by adjusting the broth cultures until the turbidity matched the 0.5 McFarland standards. A sterile cotton swab was dipped into the standardized suspension, drained and used for inoculating $20 \mathrm{ml}$ of Mueller Hinton agar (Oxoid, UK) on a 100-mm disposable plate. The inoculated plates were aseptically air-dried for 30 minutes, and antibiotic discs were impregnated on the agar plates using flamed forceps. The discs were gently pressed on the agar medium to ensure maximum contact. Discs containing the following antibiotics were used: Augmentin $^{\circledast} \quad(30 \mu \mathrm{g}), \quad$ amoxicillin $(25 \mu \mathrm{g})$, erythromycin $(5 \mu \mathrm{g})$, tetracycline $(10 \mu \mathrm{g})$, cloxacillin $(5 \mu \mathrm{g}), \quad$ cotrimoxazole $(25 \mu \mathrm{g})$, chloramphenicol $(30 \mu \mathrm{g})$, gentamicin $(10 \mu \mathrm{g})$ and ciprofloxacin $(5 \mu \mathrm{g})$. The plates were incubated aerobically at $37^{\circ} \mathrm{C}$ for 24 hours before measuring diameters of the zones of inhibition. Sensitive, intermediate and resistant strains were marked $\mathrm{S}$, I and $\mathrm{R}$ respectively as standardized by CLSI. ${ }^{[8]}$

\section{Plant Samples}

The roots, leaves, stem and flower of Nauclea latifolia were collected from the forest of Cacao Research Institute of Nigeria, Onigambari, Ibadan and they were authenticated by a botanist at the Herbarium Laboratory of the Department of Pharmacognosy, Olabisi Onabanjo University with voucher specimen number HBL323.

\section{Extraction method}

The slightly modified method of Harbone (1998) was used to prepare the extracts using Soxhlet apparatus. The air-dried sample the leaves were pulverized and extracted using the Soxhlet apparatus. Ethyl acetate and methanol were used as solvents of choice during the extraction. The crude extracts were concentrated and freeze-dried and the residues were used for phytochemical analysis.

\section{Phytochemical Screening}

Phytochemical analysis was carried out to identify some bioactive secondary metabolites in the methanol extracts of Nauclea latifolia. The secondary metabolites were detected as follows. [9]

Test for Tannins: Half a gram of the crude extract of Nauclea latifolia leaves was boiled in $10 \mathrm{mls}$ of distilled water in a test tube and then filtered. A few drops of $0.1 \%$ ferric chloride was added and observed for colour changes. Blueblack colour indicated the presence of tannins.

Test for Alkaloids: Half a gram of Nauclea latifolia leave extracts was diluted to $10 \mathrm{mls}$ with acid alcohol, boiled and filtered. Two millilitres of dilute ammonia was added to $5 \mathrm{mls}$ of the filtrate. To the extract, $5 \mathrm{mls}$ of chloroform was added and shaken gently to extract the alkaloidal base. The layer of chloroform was extracted with $10 \mathrm{ml}$ of acetic acid. This was divided into two portions. Mayer's reagent and Draggendorff's reagent was added to the first and second portion respectively. A creamy/reddish-brown precipitate was taken as positive for alkaloids.

Test for Flavonoids: Five millilitres of 10\% dilute ammonia solution was added to a portion of the aqueous filtrate of the crude extract. Concentrated sulphuric acid $(1 \mathrm{ml})$ was added. A yellow colour which disappeared on standing showed the presence of flavonoids.

Test for Saponins: Half a gram of the extract was added to $5 \mathrm{mls}$ of distilled water in a test tube. The solution was vigorously shaken and observed for a stable persistent froth. The frothing was mixed with three drops of olive oil and vigorously shaken. Thereafter, it was observed for the formation of an emulsion. 
Test for Anthraquinone: Half a gram of the extract was boiled with $10 \mathrm{mls}$ of sulphuric acid and was filtered while it is still hot. The filtrate was shaken with $5 \mathrm{mls}$ of chloroform. The resultant layer of chloroform was pipetted into another test tube and $1 \mathrm{ml}$ of dilute ammonia was added. The resultant solution was checked for colour changes.

Test for Steroids: Half a gram of the extract was dissolved in $2 \mathrm{mls}$ of chloroform. Sulphuric acid was added to the solution and a layer was formed at the lower end of the test tube. A reddish-brown colouration at the interface confirmed the presence of the steroidal ring.

\section{Determination of Minimum Inhibitory Concentrations (MICs)}

The Minimum Inhibitory Concentrations (MIC) of the extracts was determined by dissolving $0.5 \mathrm{~g}$ of extract in $10 \mathrm{mls}$ to attain a stock concentration of $50 \mathrm{mg} / \mathrm{ml}$. Furthermore, $5 \mathrm{mls}$ of the mixture was diluted serially with $5 \mathrm{mls}$ of the methanol $(50 \%)$ resulting in concentrations of $25 \mathrm{mg} / \mathrm{ml}, \quad 12.5 \mathrm{mg} / \mathrm{ml}, \quad 6.125 \mathrm{mg} / \mathrm{ml}$, $3.125 \mathrm{mg} / \mathrm{ml}$ and $1.625 \mathrm{ml}$ respectively. The same procedure was repeated for each extract with ethyl acetate. Two millilitres ( $2 \mathrm{mls}$ ) of the crude extract from each dilution were introduced into
$18 \mathrm{mls}$ of molten Mueller Hinton agar and was poured into sterile Petri-dishes and thereafter, allowed the agar to set. The surface of the agar was allowed to dry before inoculating with diluted 24-hour fresh culture of the test organisms. The agar plates were incubated at $37^{\circ} \mathrm{C}$ for 24 hours after which the lowest concentration that prevented visible growth of the organisms was taken as the Minimum Inhibitory Concentrations (MICs) of the extract.

\section{Results}

The antibiogram of Samonella typhi showed the following patterns of antimicrobial resistance: Augmentin $^{\circledast}$ (6; 24\%), amoxicillin (11; 44\%), chloramphenicol $(8 ; 32 \%)$, gentamicin $(5 ; 20 \%)$, cloxacillin (24; 96\%), ciprofloxacin $(2 ; 8 \%)$, erythromycin $(15 ; 60 \%)$, tetracycline $(8 ; 32 \%)$ and cotrimoxazole $(15 ; 60 \%)$ as shown in Table I. The extracts showed good antibacterial activity on the clinical isolates including those that were resistant to antibiotics. The MIC of methanol extracts ranged from $1.625 \mathrm{mg} / \mathrm{ml}$ to $6.125 \mathrm{mg} / \mathrm{ml}$ and $6.125 \mathrm{mg} / \mathrm{ml}$ to $12.5 \mathrm{mg} / \mathrm{ml}$ for ethyl acetate extract as shown in Table II.

Table I: Pattern of antimicrobial susceptibility among 25 Salmonella typhi isolates

\begin{tabular}{llll}
\hline Antimicrobial Agent & Resistant (\%) & Intermediate (\%) & Susceptible \\
\hline Augmentin ${ }^{\circledR}$ & $6(24.0)$ & $5(20.0)$ & $14(56.0)$ \\
Amoxicillin & $11(44.0)$ & $5(20.0)$ & $9(36.0)$ \\
Erythromycin & $15(60.0)$ & $6(24.0)$ & $4(16.0)$ \\
Tetracycline & $8(32.0)$ & $11(44.0)$ & $6(24.0)$ \\
Cloxacillin & $24(96.0)$ & $1(4.0)$ & $0(0.0)$ \\
Gentamicin & $5(20.0)$ & $5(20.0)$ & $15(60.0)$ \\
Cotrimoxazole & $15(60.0)$ & $6(24.0)$ & $4(16.0)$ \\
Chloramphenicol & $8(32.0)$ & $3(12.0)$ & $14(56.0)$ \\
Ciprofloxacin & $2(8.0)$ & $3(12.0)$ & $20(80.0)$ \\
\hline
\end{tabular}


Table II: Determination of Minimum Inhibitory Concentration (MIC) of Nauclea latifolia crude extracts on test organisms.

\begin{tabular}{|c|c|c|}
\hline Test organisms & Methanol ( $\mathrm{mg} / \mathrm{ml})$ & $\begin{array}{l}\text { Ethyl acetate } \\
(\mathrm{mg} / \mathrm{ml})\end{array}$ \\
\hline St1 & 3.13 & 12.5 \\
\hline St2 & 3.13 & 6.25 \\
\hline St3 & 6.25 & 12.5 \\
\hline St4 & 6.25 & 12.5 \\
\hline St5 & 6.25 & 25.0 \\
\hline St6 & 1.56 & 6.25 \\
\hline St7 & 3.13 & 12.5 \\
\hline St8 & 3.13 & 50.0 \\
\hline St9 & $6.25^{\prime}$ & 50.0 \\
\hline St10 & 3.13 & 12.5 \\
\hline St11 & 3.13 & 25.0 \\
\hline St12 & 6.25 & 12.5 \\
\hline St13 & 6.25 & 12.5 \\
\hline St14 & 6.25 & 12.5 \\
\hline St15 & 1.56 & 12.5 \\
\hline St16 & 3.13 & 6.25 \\
\hline St17 & 3.13 & 12.5 \\
\hline St18 & 1.56 & 6.25 \\
\hline St19 & 3.13 & 50.0 \\
\hline St20 & 1.56 & 50.0 \\
\hline St21 & 1.56 & 3.13 \\
\hline St22 & 3.13 & 6.25 \\
\hline St23 & 6.25 & 6.25 \\
\hline St24 & 1.56 & 12.5 \\
\hline St25 & 1.56 & 6.25 \\
\hline
\end{tabular}

St- Salmonella typhi

\section{Discussion}

In the present study, the antimicrobial resistance of the isolates to amoxicillin, cloxacillin, erythromycin and cotrimoxazole agrees with the existing pattern. However, susceptibility to ciprofloxacin, augmentin ${ }^{\circledast}$ and chloramphenicol is diverse. Many of the clinical isolates can be described as multidrug-resistant (MDR), haven shown resistance to three or more antibiotics belonging to different classes (cloxacillin, erythromycin, tetracycline, and cotrimoxazole). The increasing resistance of Salmonella typhi 
could be extrinsic or intrinsic depending on the prevailing phenomenon. [10]

The highest resistance of the isolates in the present study was recorded against cloxacillin (96\%). The resistance could be due to plasmid, signature mutation of DNA gyrase subunit in fluoroquinolones as well as DNA topomeirases IV components part C and part E. Also, inappropriate use of antibiotics, poor prescription and inclusion of antibiotics in consumable agricultural products could explain the resistance obtained since the isolates used were from different individuals with varied hygiene status, though in the same geographical environment. Other studies, in agreement with these findings, confirm the increase in circulation of multidrug-resistant Salmonella typhi isolates over a relatively short period. [11]

The percentage yield of methanol extract was higher $(11.73 \%)$ than for ethyl acetate extract (3.5\%). This could be as a result of a selective reaction of the composition of the extract to chemicals of different polarities. Most polar constituents were recorded in methanol, whose higher polarity makes it an excellent extractant for tannins and other polyphenolic compounds which are well known for their antimicrobial activity. This is in agreement with the phytochemical analysis which showed tannins, flavonoids and anthraquinones (all are highly polar and polyphenolic) as secondary metabolites but steroids were absent. The presence of all these secondary metabolites of therapeutic values could be a source of antimicrobial activity of the leave extract against Salmonella typhi because the pharmacological activity of several medicinal plants have been reported to be directly associated with the types of secondary metabolite they contain. [12]

The degree of inhibition varied amongst all the isolates; the MIC range of $1.56 \mathrm{mg} / \mathrm{ml}$ to $6.25 \mathrm{mg} / \mathrm{ml}$ methanol extract recorded for Nauclea latifolia was lower (therefore more active) than the MIC values of ethyl acetate extract that ranged from $3.13 \mathrm{mg} / \mathrm{ml}$ to $25.0 \mathrm{mg} / \mathrm{ml}$ ). Ethyl acetate extract of the sample had lesser activity on isolates 11, 12,19 , and 20 which results in their high MIC values of $50 \mathrm{mg} / \mathrm{ml}$ (stock concentration) in the present study while methanol had significant activity on them. From the MIC's point of view as observed in the present study, the folkloric use of Nauclea latifolia decoction to treat typhoid fever is justified. It also showed activity against strains of Salmonella typhi that were resistant to many conventional antibiotics used in this research works. [13]

While the traditional use of Nauclea latifolia for typhoid fever should not be over-emphasized, over-use and misuse of conventional antibiotics should be discouraged to minimize the upsurge of preventable antimicrobial resistance. Additional studies are recommended to characterize the active antimicrobial compounds and evaluate the in-vivo therapeutic and safety profiles of Nauclea latifolia for the treatment of enteric fever.

Authors' Contributions: OOL conceived and designed the study and conducted the data analysis. OOL drafted the manuscript. IPA and KTT participated in data collection. All the authors reviewed the draft and approved the final version of the manuscript.

Conflict of Interest: None declared. Funding: Self-funded.

Publication History: Submitted 26 December 2019; Accepted 16 May 2020.

\section{References}

1. Duke JA. Ethnobotanical uses of Nauclea latifolia. Phytochemical and Ethnobotanical 2008: Databases. 
2. Adeleke OE, Adepoju TJ, Ojo AA. Prevalence of typhoid fever and antibiotic susceptibility pattern of its causative agent, Salmonella typhi. Niger J Microbiol 2006; 20: 1191-1197.

3. Crump JA, Krestinger K, Gay K, Hoekstra RM, Vugia DJ, Hurd S,.et al. Clinical response and outcome of infection with Salmonella enterica serotype Typhi with decreased susceptibility to fluoroquinolones. Antimicrob Agent Chemother 2008; 52: 1278 1284

4. Reddy KR, Rajesh PKM, Sekar U. Antibiotic susceptibility pattern and plasmid profile of multidrug-resistant Salmonella typhi. Indian J Med Microbiol 2005; 23: 208.

5. Akinyemi KO, Smith ST, Oyefolu AO, Coker AO. Multidrug-resistance in Salmonella entericaserovar Typhi isolated from patients with typhoid fever complications in Lagos, Nigeria. Public Health 2005; 119: 321-327.

6. WHO. Traditional medicine and modern health care progress reported by the Director-General Document No A44110 WHO Geneva.1991.

7. Rukangira E. The African Herbal Industry and Challenges. www.conserveafrica.org 2000.
8. Clinical and Laboratory Standard Institute, (CLSI) Performance standard for antimicrobial disk susceptibility tests 2009 (M02-A10). Wayne, PA: CLSI

9. Harbone JB. Phytochemical methods, a guide to modern techniques of plant analysis. 3rd edition, Chapmann and Hall. London, UK. 1998; p.278.

10. Gautam V, Gupta NK, Chaudhary U, Arora DR. Sensitivity pattern of Salmonella serotypes in Northern India. Braz J Infect Dis 2002; 6: 6 .

11. Bhutta ZA, Khan IA, Shadmani M. Failure of short-course ceftriaxone chemotherapy for multidrug-resistant typhoid fever in children: a randomized controlled trial in Pakistan. Antimicrob Agents Chemother 2000; 44: 450-452.

12. Wallace JR. Antimicrobial properties of plant secondary metabolites. Proc Nutr Soc 2004; 63: 621-629.

13. Nascimento GGF, Locatelli J, Freitas PC, Silva GL. Antibacterial activity of plant extracts and phytochemicals on antibioticresistant bacteria. Braz J Microbiol 2000; 31: 247-256. 